\title{
Perception and Practice Regarding Prevention of COVID-19 among Community People During and After Lockdown
}

\author{
Poonam Shah ${ }^{1 *}$, Sanjana Shah ${ }^{1}$, Laxmi Shah ${ }^{1}$, Shree Shyam Giri ${ }^{1}$, Shambhu Prasasd Kushwaha ${ }^{2}$, \\ Lokeshwar Chaurasia $^{3}$
}

${ }^{1}$ College of Nursing, Sinha Health Foundation Pvt. Ltd., Janakpur, Nepal

${ }^{2}$ District Health Office, Dhanusha, Janakpur, Nepal.

${ }^{3}$ Department of Pharmacology, Janaki Medical College, Janakpur, Nepal

ARTICLE INFO
Article history:
Received: 17 March 2021
Revised: 27 April 2021
Accepted: 11 June 2021
*Correspondence:
Mrs. Poonam Shah
College of Nursing,
Sinha Health Foundation
Pvt. Ltd., Janakpur, Nepal
E-mail:
shpoonam77@gmail.com
People During and After
Lockdown. MedS. J. Med.
Sci. 2021;1(1):25-31

\section{INTRODUCTION}

Due to erratic growth of COVID-19 across the globe, World Health Organization (WHO) confirmed it as a public health emergency of international concern (PHEIC) on 30 Jan 2020. After verifying the outbreak at perturbing levels of spread and severity, on March 11, WHO characterized COVID-19 as a pandemic. The mortality and morbidity of COVID-19 is rapidly changing across the world. Currently, the Coronavirus disease has spread to more than 200 countries with nearly 175541600 confirmed cases and 3798361 recorded deaths [1]. In Nepal, confirmed cases of COVID-19 had risen to 610,521 and 8,465 deaths as of 14th June 2021 [2].

Nepal had initiated several preventive measures such as strengthened the health desk in International and other airports, closed NepalChina border, established temporary dedicated corona hospital in various parts of the country. On 24 March, Government of Nepal announced a lockdown, which was extended for the seventh time 
until 2 June, 2020. In addition, the containment of the disease is possible only with the change in behaviours as preventive measures [3].

Public health preventive actions such as hand washing, social distancing, travel restrictions, case detection, contract tracing, quarantine, have been taken through collaborative efforts from all countries [4]. As a part of the emergency response activities across all states, Government of Nepal with their partners launched an education campaign to stay safely in the context of the COVID-19 pandemic and beyond, with information to prevent the spread of infection. These campaigns have been aimed at knowledge improvement on precautionary measures such as wearing of face masks, regular handwashing with soap and water or with alcohol-based hand sanitizers, and social distancing among community members [5]. Evidences show that perception shapes one's knowledge and hence improve the adoption of precautionary measures on the transmission of an infection [6]. An assessment of the perception and practices of community members is important to reduce the risk for COVID-19 infection. Literature from several studies shows the perception of community members regarding COVID-19 could help target interventions needed to improve the knowledge and perception of community members and hence enhance the preventive practice regarding COVID-19 [6-9]. Therefore, this study aims to assess and compare the perception and practice regarding prevention of COVID-19 among community people during and after lockdown.

\section{MATERIALS AND METHODS}

Study design and setting

A cross-sectional study was conducted among community sample from November, 2020 to January, 2021 at Janakpur sub-metropolitan city of Dhanusha district, Province-2, Nepal. The city is located in Terai region of Nepal and is a hub for religious and cultural tourism. As of 2015, the city had a population of 173,924 , making it the largest sub-metropolitan city of Nepal. The majority of the city's population speak Maithili language [10].

\section{Sample size and sampling}

The sample size was calculated using a formula for descriptive cross-sectional study. The population of the selected metropolitan city is $>100,000$. The sample size was calculated using the Leslie Kish formula for sample size determination for a single proportion as follows: $\mathrm{n}=\mathrm{Z}^{2} \mathrm{pq} / \mathrm{d}^{2}$ where, $\mathrm{n}$ is the minimum desired sample size, $\mathrm{Z}$ is the standard normal deviate, usually set as 1.96 which corresponds to $5 \%$ level of significance, $p$ was used as $50 \%$ for maximum sample and $d$ is the degree of accuracy (precision) set at $5 \%$. This yields a sample of 384 participants. Additional, 10\% was considered for potential non-response. Therefore, total sample calculated was 422 . Two stages random sampling technique was used to select the study sample. First, Janakpur sub-metropolitan city was selected for the study. There were 27 wards in Janakpur submetropolitan city. Out of 27, two wards were selected randomly. Second, a center location was chosen in the both selected ward. A coin was tossed to determine the direction of movement for selection of households for the interview. From the outcome of the coin; head for right direction and tail for left direction; all the households were chosen and the head of the households were included in the study until 211 were interviewed in both selected area consisting total of 422 sample. Community people present at their households at the time of survey were included in the study. People who were mentally disabled were excluded from the study.

\section{Data collection}

A structured questionnaire was administered through face to face interview to know the perception and practice regarding prevention of COVID-19 infection before and after lockdown. The questionnaire has two sections. Section A: Baseline questionnaire including the demographic variables like age, sex, educational status, marital status. Section B: 4- point Likert's scale was used as Large extent/ Moderate extent/ Small extent / Very small extent for the perception and 3-point Likert's scale was used as Always/Sometimes / Rarely for the practices regarding prevention of COVID-19 infection among community people during and after lockdown. The questionnaires was prepared in English language then converted into Nepali. Pretesting of the tool was done by conducting in small survey consisting $5 \%$ of total small size in neighbouring municipality.

Ethical approval for the study was obtained from the concern authority with reference number $12 / 2077 / 78$. Permission for the study was obtained from the respondents and the confidentiality of 
information was maintained. The respondents were informed of their right to decline or withdraw from the study at any time without any adverse consequences. No harm was inflicted on participants because of participation in this study.

\section{Statistical considerations}

Data were entered into Microsoft excel and was transferred to SPSS version 21 for analysis. Frequencies and percentages were used to present the categorical variables. Responses from the respondents for perception and practices were classified into two categories for the analysis. For perception category were large or moderate extent Vs. small or very small extent whereas for the practices the category were always Vs. sometimes or rarely. McNemar Chi-square test was used to assess the association during and after lockdown for each component of perception and practices for the prevention of COVID-19 infection. P-values less than 0.05 were considered as significant.

\section{RESULTS}

A total of 422 respondents, majority of the participants were male $(68.6 \%)$ and married $(65 \%)$. More than half $(52.1 \%)$ of the participants were aged 40 years and $54.5 \%$ had secondary level of education. Few participants $(12.8 \%)$ had income between 30,000 and 60,000 of Nepalese rupees (Table 1).

\begin{tabular}{cccc}
\hline Table 1 | Socio demographic characteristics of participants $(\mathrm{n}=422)$ & & \\
\hline Variables & Category & Number & Percentage \\
\hline Age (year) & $<20$ & 25 & 06.0 \\
& $20-40$ & 177 & 42.1 \\
\multirow{3}{*}{ Gender } & $40 \&$ more & 220 & 52.1 \\
& Female & 133 & 31.5 \\
Marital status & Male & 290 & 68.5 \\
& Married & 274 & 65.0 \\
Education & Unmarried & 148 & 35.0 \\
& Illiterate & 45 & 10.6 \\
& Primary & 92 & 21.8 \\
& Secondary & 230 & 54.5 \\
Monthly Income (Nrs.) & Higher secondary \& above & 57 & 13.6 \\
& $<30000$ & 48 & 11.4 \\
& 30000-60000 & 54 & 12.8 \\
& $>60000$ & 47 & 11.1 \\
& No response & 273 & 64.7 \\
\hline
\end{tabular}

The perception regarding prevention of COVID-19 infection among community people alleviated after lockdown compared to the perception during lockdown for each component; COVID-19 was observed in your community $(69.0 \%$ vs $67.3 \%$; $\mathrm{p}=0.608$ ), preventive measures against COVID-19 ( $73.3 \%$ vs $63.5 \%$; $=0.002)$, considering risk of getting COVID-19 (67.5\% vs $73.0 \%$; $p=0.474)$, family members concerned about getting $(60.7 \%$ vs $55.9 \%$; $\mathrm{p}=0.152)$, extent of thinking COVID-19 as dangerous and deadly (64.5\% vs $59.0 \%$; $\mathrm{p}=0.09)$, suspicion of having COVID-19 to hold selfresponsible for the health of others and followed the preventive measures more precisely $(59.2 \%$ vs
$58.1 \%$; $\mathrm{p}=0.758$ ), extent of COVID-19 had a negative influence on routine life $(64.5 \%$ vs $62.3 \%$; $p=0.529)$ and extent of washing hands with soap and water can help in prevention of COVID -19 transmission (66.8\% vs 63.7\%; $\mathrm{p}=0.322$ ). However, perception regarding afraid of getting COVID-19 by themselves and their family members were elevated after lockdown $(64.2 \%$ vs $59.0 \% ; \mathrm{p}=0.113)$ and $(59.7 \%$ vs $62.8 \% ; \mathrm{p}=0.332)$ respectively than the perception during lockdown. The perception among community people regarding prevention of COVID-19 during and after lockdown was insignificant for all the component $(p>0.05)$ except 
perception regarding preventive measures against COVID-19; $\mathrm{p}=0.002)$ (Table 2).

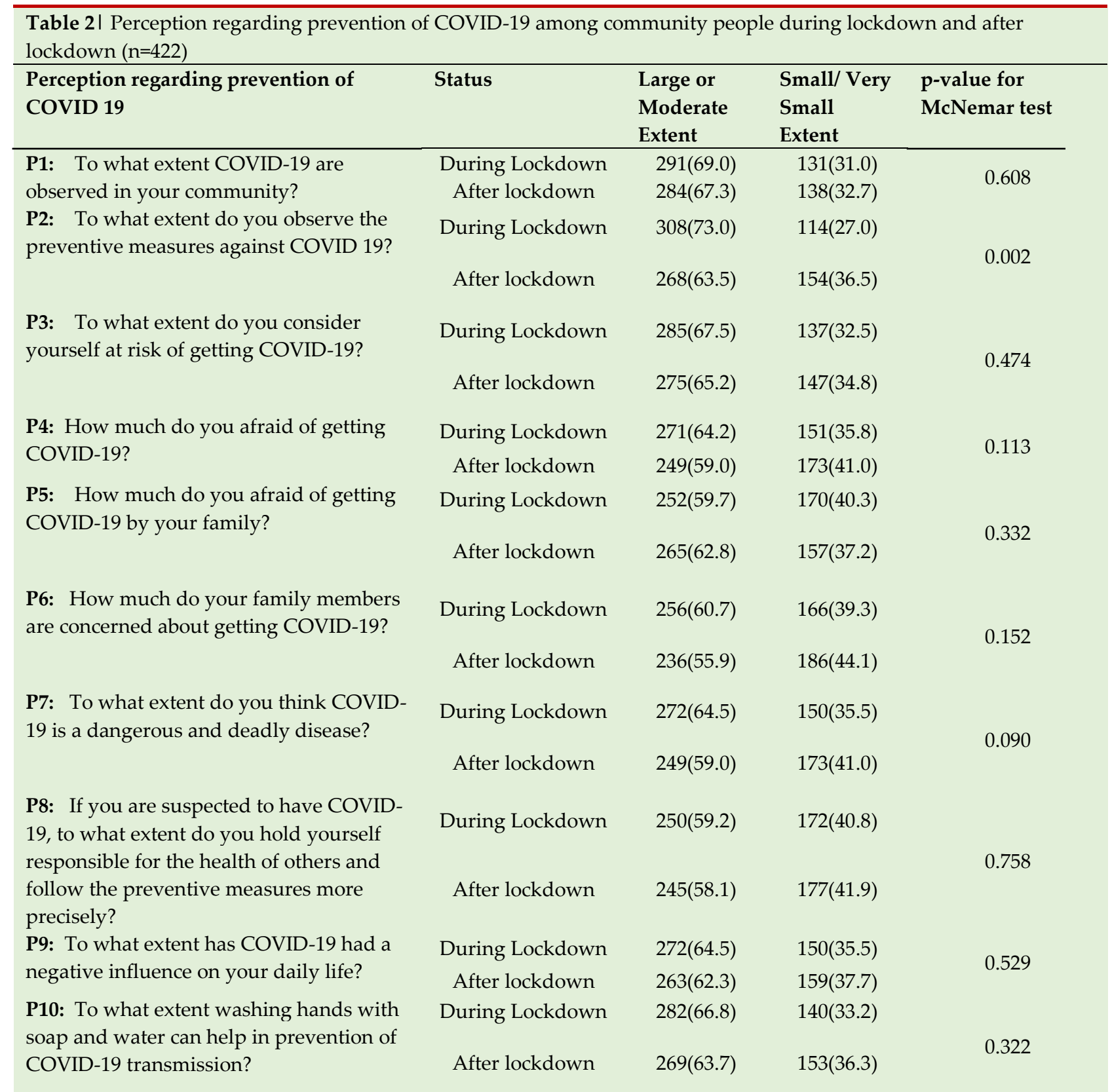

Table 3 shows practice regarding prevention of COVID- 19 among community people during and after lockdown. The practices for prevention of COVID-19 infection among community people decreased after lockdown compared to the practices during lockdown for each component; washing or disinfecting hands ( $41.5 \%$ vs $31.7 \%$ ), avoid touching face and eyes with unwashed hands $(38.4 \%$ vs $28.2 \%$ ), use of mask ( $45.5 \%$ vs $26.8 \%$ ), use of face mask, paper tissue, or elbow when sneezing or having runny nose $(44.3 \%$ vs $24.9 \%)$, regular disinfection of surface and personal objects and places (39.3\% vs $24.2 \%$ ), keeping themselves at least
1.0 to 1.5 meter distance from others $(46.9 \%$ vs $21.8 \%$ ), following news of COVID-19 (43.1\% vs $28.4 \%$ ), trying to teach other people about the prevention of COVID-19 (48.6\% vs $28.9 \%$ ) and practice regarding family cooked egg or meat properly before consumption ( $48.6 \%$ vs $39.3 \%$ ) but practice for hand shaking with others was increased $(22.3 \%$ vs $51.4 \%)$ after lockdown compared to during lockdown. The practices for prevention of COVID-19 for all the components among community people during and after lockdown was found to be significant $(\mathrm{p}<0.0001)$. 
Table 3। Practice regarding prevention of COVID-19 among community people during lockdown and after lockdown $(\mathrm{n}=422)$

\begin{tabular}{|c|c|c|c|c|}
\hline Practice during lockdown & Status & Always & $\begin{array}{l}\text { Sometimes / } \\
\text { Rarely }\end{array}$ & $\begin{array}{l}\text { p-value for } \\
\text { McNemar test }\end{array}$ \\
\hline \multirow{2}{*}{$\begin{array}{l}\text { P1: How often do you wash or disinfect your } \\
\text { hands? }\end{array}$} & During Lockdown & $175(41.5)$ & $247(58.5)$ & \multirow{2}{*}{0.001} \\
\hline & After lockdown & 134(31.7) & $288(68.3)$ & \\
\hline \multirow{2}{*}{$\begin{array}{l}\text { P2: How often do you avoid touching your } \\
\text { face and eyes with unwashed hands? }\end{array}$} & During Lockdown & $162(38.4)$ & $260(61.6)$ & \multirow{2}{*}{0.001} \\
\hline & After lockdown & $119(28.2)$ & $303(71.8)$ & \\
\hline \multirow[t]{2}{*}{ P3: How often do you use mask? } & During Lockdown & 192(45.5) & $230(54.5)$ & \multirow{2}{*}{$<0.0001$} \\
\hline & After lockdown & $113(26.8)$ & $309(73.2)$ & \\
\hline \multirow{2}{*}{$\begin{array}{l}\text { P4: How often do you use face mask, paper } \\
\text { tissue, or elbow when sneezing or having } \\
\text { runny nose? }\end{array}$} & During Lockdown & $187(44.3)$ & $235(55.7)$ & \multirow[b]{2}{*}{$<0.0001$} \\
\hline & After lockdown & $105(24.9)$ & $317(75.1)$ & \\
\hline \multirow{2}{*}{$\begin{array}{l}\text { P5: How often do you regularly disinfect } \\
\text { surfaces of personal objects and places? }\end{array}$} & During Lockdown & 166(39.3) & $256(60.7)$ & \multirow{2}{*}{$<0.0001$} \\
\hline & After lockdown & $102(24.2)$ & $320(75.8)$ & \\
\hline \multirow{2}{*}{$\begin{array}{l}\text { P6: How often do you shake hands with } \\
\text { others? }\end{array}$} & During Lockdown & $94(22.3)$ & $328(77.7)$ & \multirow{2}{*}{$<0.0001$} \\
\hline & After lockdown & $217(51.4)$ & 205(48.6) & \\
\hline \multirow{2}{*}{$\begin{array}{l}\text { P7: How often do you keep at least } \\
\mathrm{m} \text { distance from others? }\end{array}$} & During Lockdown & 198(46.9) & $224(53.1)$ & \multirow{2}{*}{$<0.0001$} \\
\hline & After lockdown & $92(21.8)$ & $330(78.2)$ & \\
\hline \multirow{2}{*}{$\begin{array}{l}\text { P8: How often do you follow news about } \\
\text { news about COVID 19? }\end{array}$} & During Lockdown & 182(43.1) & $240(56.9)$ & \multirow{2}{*}{$<0.0001$} \\
\hline & After lockdown & $120(28.4)$ & $302(71.6)$ & \\
\hline \multirow{2}{*}{$\begin{array}{l}\text { P9: How often do you try to teach other } \\
\text { people about prevention of getting COVID-19 } \\
\text { ? }\end{array}$} & During Lockdown & 205(48.6) & $217(51.4)$ & \multirow{2}{*}{$<0.0001$} \\
\hline & After lockdown & $122(28.9)$ & $300(71.1)$ & \\
\hline \multirow{2}{*}{$\begin{array}{l}\text { P10: How often do you or your family cook } \\
\text { eggs or meat properly before consumption? }\end{array}$} & During Lockdown & 205(48.6) & $217(51.4)$ & \multirow{2}{*}{0.003} \\
\hline & After lockdown & $166(39.3)$ & $256(60.7)$ & \\
\hline
\end{tabular}

\section{DISCUSSION}

A total of 422 respondents participated in this survey. Majority of study participants were male $68.6 \%, 65 \%$ were married, $49 \%$ were aged between 40-60 years. Most of the participants (54.5\%) were educated up to higher secondary level of education and few $(12.8 \%)$ had monthly income between of 30,000-60,000 in Nepalese rupees. The finding is similar to the study conducted by Honarvar B et al. where the majority of respondent were male (56.1\%) and $42.1 \%$ were between age group 30-60 years and $45.7 \%$ were educated and few (9.3\%) had family income between 30000-60000, and 52.1\% were married [11].

More than half of the respondents agreed to a larger or moderate extent that COVID-19 infection was observed in their communities, considered themselves at risk of getting COVID-19, were afraid of getting COVID-19 by themselves and their family members, family members were concerned about getting it, thought COVID-19 as dangerous and deadly, were suspicious of having COVID-19 to hold self- responsible for the health of others and followed the preventive measures more precisely, extent of COVID-19 had a negative influence on routine life, washing hands with soap and water can help in prevention of COVID -19 transmission and perception regarding extent to observe the preventive measures against COVID-19 during lockdown and after lock down as well.

In line with this study, a study conducted in India [12] reported that most people have right perception towards COVID-19; whereas in Nepal revealed that positive perception existed towards COVID-19 universal safety measures, however negative perception also existed like COVID-19 attacked only older people; and coughing into the 
elbow was not good practice to prevent the spread of the virus [13, 14]. Studies from Nepal [15, 16], India [17], Bangladesh [18], Sri Lanka [19] and China [20] also showed a positive perception regarding the prevention of COVID-19. Moreover, we did not find a significant difference during and after lockdown for any component of perception on prevention of COVID-19 among community people. In our study, less than half of the participants always practiced for the prevention of COVID-19 infection such as washing or disinfecting hands, touching face and eyes with unwashed hands, use of mask, use of face mask, paper tissue, or elbow when sneezing or having runny nose, regularly disinfecting surface and personal objects and places, hand shaking with others, keeping themselves at least 1.0 to 1.5 meter distance from others, following news of COVID-19, trying to teach other people about the prevention of COVID-19 and practice of properly cooked egg or meat before consumption, but more than half of the participants practiced hand shaking with others. The findings of the study is similar to the study conducted by Honarvar B. et al. in Iran where half $(50.8 \%)$ of the respondents believed in washing hands always [11]. Another study in India showed right practices towards COVID-19 pandemic among the respondents [12]. Several other studies from Nepal [15, 16], India [17], Bangladesh [18], Sri Lanka [19] and China [20] aligning with this study, showed fair practices for the prevention of COVID-19 infection. Additionally, we found significant lowered practices for all the component after lockdown on the prevention of COVID-19 compared to the practices during lockdown $(\mathrm{p}<0.0001)$ among community people. The finding showed increased risk of contracting COVID-19 among community people after lock down. Therefore, there is an immediate need to sensitize on COVID-19 prevention as recommended by the World Health Organization [21] to promote better practices among community people in Nepal.

To the best of our knowledge, this is the first study conducted in Nepal to assess the perception and practices regarding prevention of COVID-19 among community people. Although, this suggests similarity for the perception regarding prevention of COVID-19 during and after lockdown among community people, it cannot be concluded that risk of getting COVID-19 is low.

A right perception about COVID-19 can encourage good practices among the community people. It suggests providing educational programmes to rectify perception about COVID-19 and hence improving the practices for the prevention of COVID-19 among community people. The current study explored the public perception towards prevention and practice on COVID-19 and the findings can help public health policy makers to formulate COVID-19 education and prevention programs by identifying the target population. However, the study has several limitations.

First and foremost, this study was limited to the perception and practices regarding COVID-19, level of knowledge among community people was not assessed. Secondly, participants were chosen from a single sub-metropolitan city, the generalization of the findings is, therefore, limited. Thirdly, respondents may give false information due to recall bias as the survey questionnaire was administered to the participants at the same time for both (during the lockdown and after lockdown) responses.

\section{CONCLUSIONS}

The main purpose of this study was to assess perception and practice regarding prevention of COVID-19 among community people during and after lockdown in Janakpur sub metropolitan city. The study showed decreased practices among community people after lockdown for the prevention of COVID-19 compared to practices during lockdown. However, perception remains unchanged during and after lockdown for the prevention of COVID-19. Therefore, community people of Janakpur sub metropolitan city needs to improve their practices on prevention of COVID-19 even after lockdown. The government and nongovernment agencies should implement awareness program to improve and continue the practices for the prevention of COVID-19 through mass media and social campaigns. Additional research is needed to sort-out issue on the prevention of COVID-19. 


\section{ADDITIONAL INFORMATION AND DECLARATIONS}

Acknowledgements: The authors express their gratitude to all participants for their cooperation to participate in this study.

Funding: The authors received no funding for this work.

Competing Interests: The authors declare no competing interests.

Author Contributions: Concept and design: P.S. and S.S.; statistical analysis: P.S., S.S. and L.S.; writing of the manuscript: P.S., S.S., S.S.G., and S.P.K.; revision and editing the manuscript:
P.S., S.S., S.S.G., and S.P.K.. All authors contributed to allanalysis, interpretation of results, literature review, and revision of the manuscript, and all have read and agreed with the contents of the final manuscript.

Data Availability: Data will be available up on request to corresponding authors after valid region.

\section{REFERENCES}

1. World Health Organization (WHO), Coronavirus disease (COVID-19) pandemic. 2021 [cited 14 June 2021].

2. World Health Organization (WHO), Health Emergency Dashboard, Nepal Situation, Daily (COVID-19), Dashboard. 2021 [cited 14 June 2021].

3. Health Sector Emergency Response Plan COVID-19 Pandemic, Government of Nepal, Ministry of Health and Population. 2020.

4. Reuben RC, Danladi MM, Saleh DA, Ejembi PE. Knowledge, attitudes and practices towards COVID-19: an epidemiological survey in North-Central Nigeria. J Community Health. 2021;46:457-70.

5. UNICEF. Government of Nepal and partners launch campaign to mitigate learning loss wrought by COVID-19. 2021.

6. Ilesanmi O, Afolabi A. Perception and practices during the COVID-19 pandemic in an urban community in Nigeria: a cross-sectional study. PeerJ. 2020;8:e10038.

7. Lee M, Kang B-A, You M. Knowledge, attitudes, and practices (KAP) toward COVID19: a cross-sectional study in South Korea. BMC Public Health. 2021;21:1-10.

8. Kandel S, Lamsal M, Yadav SA et al. Lifestyle, behavior, perception and practices of Nepalese during lockdown due to COVID-19 pandemic. JNMA J Nepal Med Assoc. 2020;58:690.

9. Paudel S, Shrestha P, Karmacharya I, Pathak OK. Knowledge, attitude, and practices (KAP) towards COVID19 among Nepalese residents during the COVID-19 outbreak: An online cross-sectional study. 2020.

10. Wikipedia. Janakpur. 2020.

11. Honarvar B, Lankarani KB, Kharmandar A et al. Knowledge, attitudes, risk perceptions, and practices of adults toward COVID-19: a population and field-based study from Iran. International journal of public health. 2020;65: 731-9.

12. Narayana G, Pradeepkumar B, Ramaiah JD et al. Knowledge, perception, and practices towards COVID-19 pandemic among general public of India: A cross-sectional online survey. Current medicine research and practice. 2020;10:153-9.

13. Singh DR, Sunuwar DR, Karki K et al. Knowledge and perception towards universal safety precautions during early phase of the COVID-19 outbreak in Nepal. J Community Health. 2020;45:1116-22.

14. Bhatt N, Bhatt B, Gurung $S$ et al. Perceptions and experiences of the public regarding the COVID19 pandemic in Nepal: a qualitative study using phenomenological analysis. BMJ open. 2020; 10:e043312.

15. Hussain A, Garima T, Singh BM et al. Knowledge, attitudes, and practices towards COVID-19 among Nepalese Residents: A quick online cross-sectional survey. Asian Journal of Medical Sciences. 2020;11:6-11.

16. Devkota HR, Sijali TR, Bogati R et al. How does public knowledge, attitudes, and behaviors correlate in relation to COVID-19? A community-based cross-sectional study in Nepal. medRxiv. 2020.

17. Acharya R, Gundi M, Ngo $T$ et al. COVID-19-related knowledge, attitudes, and practices among adolescents and young people in Bihar and Uttar Pradesh, India. Population council. 2020.

18. Islam S, Emran GI, Rahman E et al. Knowledge, attitudes and practices associated with the COVID-19 among slum dwellers resided in Dhaka City: a Bangladeshi interview-based survey. Journal of Public Health. 2021;43:13-25.

19. Weerasinghe $T$, Goonewardene C. Knowledge, attitude and the practices towards preventive measures of COVID-19 and associated factors among employees of selected companies in Colombo Municipality area, Sri Lanka. 2021.

20. Gao $\mathrm{H}, \mathrm{Hu} \mathrm{R}$, Yin $\mathrm{L}$ et al. Knowledge, attitudes and practices of the Chinese public with respect to coronavirus disease (COVID-19): an online cross-sectional survey. BMC Public Health. 2020;20:1-8.

21. Workd Health Organization, Coronavirus disease (COVID-19) advice for the public. 2021. 